Tropical Journal of Pharmaceutical Research April 2011; 10 (2): 133-140

(C) Pharmacotherapy Group Faculty of Pharmacy, University of Benin,

Benin City, 300001 Nigeria.

All rights reserved.

Research Article

Available online at http://www.tjpr.org

\title{
Prevention of Radiocontrast-Induced Nephropathy after Coronary Angiography: N-Acetylcysteine plus Saline Hydration versus Saline Hydration
}

\section{Yahaya Hassan ${ }^{1 *}$, Zainol A Zainal ${ }^{1}$, Noorizan A Aziz ${ }^{1}$, Samah W Al-Jabi ${ }^{1}$ and Omar Ismail ${ }^{2}$}

${ }^{1}$ Clinical Pharmacy Program, School of Pharmaceutical Sciences, Universiti Sains Malaysia (USM), ${ }^{2}$ Cardiology Department, Hospital Pulau Pinang, Penang, Malaysia

\begin{abstract}
Purpose: To compare the incidence of radiocontrast-induced nephropathy (RCIN) in patients undergoing coronary angiography pretreated with $\mathrm{N}$-acetylcysteine NAC plus saline hydration or saline hydration alone and to determine the association between various risk factors and RCIN.

Methods: Patients were retrospectively evaluated over a one-year period. RCIN was defined as an acute rise in serum creatinine of at least $0.5 \mathrm{mg} / \mathrm{dl}$ or more than $25 \%$ from baseline value. SPSS software, version 13 was used for data analysis.

Results: Overall, 299 patients were studied. Thirteen patients (4.3\%) developed RCIN. RCIN was $3.3 \%$ in patients treated with hydration, and $8.3 \%$ in patients treated with NAC plus hydration $(p=0.09)$. In patients with RCIN, the changes in creatinine and \% change in creatinine after $24 \mathrm{~h}$ were significantly lower in the NAC plus hydration group ( $p=0.039$ and $p=0.042$, respectively). $R C I N$ was significantly associated with male gender $(p=0.017)$, history of renal failure $(p=0.006)$, ischemic heart disease $(p=$ 0.003), and diuretic treatment $(p=0.013)$.

Conclusion: NAC plus saline hydration may not be more effective than saline hydration alone in decreasing RCIN after coronary angiography. Additional efforts to find an ideal preventive treatment are needed.

Keywords: Coronary angiography, $\mathrm{N}$-acetylcysteine, Radiocontrast-induced nephropathy, Saline hydration
\end{abstract}




\section{INTRODUCTION}

Coronary angiography is the test that requires the administration of a radiocontrast medium to reveal the location and degree of coronary stenosis or obstruction due to plaque formation. This radiocontrast medium (usually iodine-based) can contribute to the development of nephropathy [1].

Radiocontrast-induced nephropathy (RCIN) is defined as the acute deterioration of renal function that occurs two to seven days after administration of radiocontrast media in the absence of other causes [2]. It is associated with increased morbidity and mortality [3], as well as increased health care costs [4]. There are many identified risk factors for RCIN, the most common ones being pre-existing renal insufficiency and diabetes [5].

Hydration (using solutions such as isotonic saline, half-isotonic saline, dextrose solution, and sodium bicarbonate) remains the cornerstone for preventing RCIN [6]. N-acetylcysteine (NAC) is another potential option that reduces RCIN. NAC, a thiol-containing antioxidant, is thought to act either as a free-radical scavenger or as a reactive sulfhydryl compound that increases the reducing capacity of the cell [7]. It also combines with nitric oxide to form $S$-nitrosothiol, which is a more stable compound and is also a potent vasodilator [8].

A previous study had illustrated the protective effects of NAC as an adjunct to saline hydration against RCIN in low-risk patients [8]. However, contradictory results regarding effectiveness of NAC have been reported, and the protective effect of NAC is unclear $[9,10]$. In Malaysia, data on the use of NAC in patients undergoing coronary angiography are lacking. Furthermore, the incidence and prevalence of RCIN in local hospitals have not yet been reported. This retrospective study was conducted with the following aims: 1) to compare the incidence of RCIN in patients undergoing coronary angiography after pretreatment with NAC plus standard saline hydration versus standard saline hydration alone, and 2) to determine the association between various risk factors and the occurrence of RCIN.

\section{SUBJECTS AND METHODS}

\section{Settings and Study Design}

This was a retrospective cohort study of all patients admitted to Penang General Hospital,
Penang, Malaysia, who underwent coronary angiography and received standard saline hydration alone or in combination with NAC as a preventive treatment. The Penang General Hospital, the largest public hospital in Penang, Northern Malaysia, is a 1,200-bed general hospital run by the Ministry of Health of Malaysia. Approval from the health authorities was obtained before this study was initiated.

\section{Participants}

Patients were conveniently sampled from July 2006 until June 2007 from the Interventional Catheterization Lab (ICL). They were identified through a record book maintained by the staff at ICL. The record book kept details of patients who had undergone various diagnostic or interventional cardiology procedures. Sample size was calculated using a free software developed by the Department of Biostatistics, Vanderbilt University, USA (PS: Power and Sample Size Calculation version 3.0). These data were entered into the database to calculate sample size, and examine dichotomous outcomes (nephropathy versus no nephropathy): $\alpha=0.05$, power $=0.9, P_{0}=0.1, P_{1}=$ $0.3, M=1$. The calculated sample size was 62 patients for each group. Furthermore, during the one-year study, 512 medical records were screened, but only 299 records were found to be complete for further evaluation. Sixty patients were prophylactically treated with NAC and hydration. The remaining 239 patients were treated with prophylaxis hydration for the prevention of RCIN. Patients were excluded if they were below the age of 18; if they had undergone other coronary procedures besides angiography, such as coronary stenting and bypass grafting; or if their serum creatinine levels were not documented.

\section{Study protocol}

Data were collected using special data collection forms and classified into several categories including the following: age; gender; ethnicity; weight; height; body mass index; past medical history; smoking; medical condition; current medications; renal profile at $24,48,72$ and $96 \mathrm{~h}$ after radiocontrast media exposure; and radiocontrast media volume. In all cases, iopromide $\left(\right.$ Ultravis $\left.{ }^{\Theta}\right)$, which is a nonionic, lowosmolar contrast medium, was used.

Radiocontrast-induced nephropathy was defined as an acute rise in serum creatinine of at least 0.5 $\mathrm{mg} / \mathrm{dl}(44 \mu \mathrm{mol} / \mathrm{L})$ or more than $25 \%$ from 
baseline value [11]. Creatinine clearance $(\mathrm{CrCl})$ was determined for each patient and was calculated using the Cockcroft-Gault formula, where $\mathrm{CrCl}=([140-$ age $] \times$ weight $(\mathrm{kg}) /$ serum creatinine $(\mathrm{mg} / \mathrm{dl}) \times 72)$, with adjustment for female sex $\left(\mathrm{CrCl}_{\text {female }}=\mathrm{CrCl} \times 0.85\right)$ [12]. Further, the Mehran risk score was estimated; this score reflects the risk of contrast nephropathy before the procedure. The Mehran risk score was calculated according to several risk factors, including baseline creatinine clearance, dose of contrast media, older age, hypotension, anemia, heart failure, diabetes, and the use of an intra-aortic balloon pump [13].

\section{Data analysis}

The data were entered and analyzed using Statistical Package for Social Sciences, version 13 (SPSS Inc., Chicago, Illinois) for Windows. Continuous variables were expressed as mean ( \pm standard deviation), and categorical data were expressed as frequency and percentage. Variables that were not normally distributed were expressed as median (lower-upper quartiles). Comparisons between two variables that were normally distributed were carried out using the independent sample t-test. Variables were tested for normality using the Kolmogorov-Smirnov test; if assumptions of the equality of variance and normality were not met, the Mann-Whitney $U$ test was performed as appropriate. Categorical variables were analyzed using the Chi-Square test or Fisher's exact test, Fisher's exact test was used in analyzing the $2 \times 2$ tables with an expected cell frequency of $<10$. Probability values of $<0.05$ were considered significant.

\section{RESULTS}

\section{Baseline characteristics}

A total of 299 patients were evaluated in this study; $239(79.9 \%)$ patients received standard saline hydration alone, and $60(20.1 \%)$ patients received standard saline hydration plus NAC as a preventive treatment.

Table 1 compares the baseline demographic and clinical characteristics of patients among both groups and shows that patients in the NAC plus standard saline hydration group had significantly lower creatinine clearance $(p<0.001)$, higher serum creatinine $(p<0.001)$, as well as higher prevalence of renal insufficiency $(p=0.035)$, diabetes mellitus $(p=0.012)$, anemia $(p=0.012)$ and hypertension $(p=0.001)$. Using the Mehran Score, patients in the NAC plus standard saline hydration group were significantly more likely to be at moderate to high risk of developing RCIN than patients in the standard saline hydration group $(p$ $=0.001)$; in contrast, patients in the standard saline hydration were more likely to be at low risk of developing RCIN $(p<0.001)$.

\section{Incidence of RCIN among both groups}

The overall incidence of RCIN was $4.3 \%$ (13 of 299 ) in the study population. RCIN was detected in eight of the 239 patients (3.3\%) in the standard saline hydration group and five of the 60 patients $(8.3 \%)$ in the NAC plus standard saline hydration group. There was no significant difference in the development of RCIN between the two groups ( $p=$ 0.09).

In the standard saline hydration group, RCIN developed after radiocontrast media exposure within $24 \mathrm{~h}$ in five patients, within $48 \mathrm{~h}$ in two patients, and within $96 \mathrm{~h}$ in a single patient. In the NAC plus hydration group, RCIN developed after radiocontrast media exposure within $24 \mathrm{~h}$ in three patients, within $72 \mathrm{~h}$ in one patient, and within $96 \mathrm{~h}$ in another patient.

\section{Comparison of creatinine-related markers of RCIN among the two groups}

Table 2 shows that the changes in serum creatinine $(p=0.039)$ and in percent serum creatinine level $(p=0.042)$ after $24 \mathrm{~h}$ were smaller in the NAC plus standard saline hydration group than the standard saline hydration group. Also, there were significant differences between the two groups regarding the changes in creatinine level $48 \mathrm{~h}$ after radiocontrast media administration $(p=$ 0.008).

\section{Risk factors associated with the development of RCIN}

The results of analysis of demographic, clinical characteristics and other risk factors of 299 patients according to the occurrence of RCIN are shown in Table 3. In comparison to patients who did not develop RCIN, patients who developed RCIN were more likely to be male $(p=0.017)$, have a history of renal failure $(p=0.006)$ or ischemic heart disease $(p=0.003)$, and be on diuretics $(p=0.013)$. 
Table 1: Demographic and baseline clinical characteristics of the patients in the standard saline hydration group and the standard saline hydration plus NAC group

\begin{tabular}{|c|c|c|c|}
\hline Baseline characteristics & $\begin{array}{l}\text { Standard saline hydration } \\
\text { group }(\mathrm{N}=239)\end{array}$ & $\begin{array}{l}\text { NAC+ standard saline } \\
\text { hydration group }(N=60)\end{array}$ & $p$-value \\
\hline Age (year) $^{a}$ & $55.9 \pm 9.3$ & $59.7 \pm 9$ & 0.005 \\
\hline \multicolumn{4}{|l|}{ Gender, n (\%) } \\
\hline Male & $164(68.6 \%)$ & $47(78.3 \%)$ & \multirow[t]{2}{*}{0.139} \\
\hline Female & $75(31.4 \%)$ & $13(21.7 \%)$ & \\
\hline \multicolumn{4}{|l|}{ Ethnic group, $\mathrm{n}(\%)^{\mathrm{b}}$} \\
\hline Malay & $93(38.9 \%)$ & $36(60.0 \%)$ & 0.003 \\
\hline Indian & $86(36 \%)$ & $16(26.6 \%)$ & 0.173 \\
\hline Chinese & $60(25.1 \%)$ & $7(11.7 \%)$ & 0.026 \\
\hline Other & $0(0 \%)$ & $1(1.7 \%)$ & 0.200 \\
\hline BMI $\left(\mathrm{kg} / \mathrm{m}^{2}\right)^{\mathrm{a}}$ & $26.1 \pm 7.1$ & $26.6 \pm 3.9$ & 0.132 \\
\hline Active smoking status, $\mathrm{n}(\%)^{\mathrm{b}}$ & $54(22.6 \%)$ & $13(21.7 \%)$ & 0.878 \\
\hline Contrast dose $(\mathrm{mL})^{a}$ & $53.5 \pm 24.5$ & $55.0 \pm 29.6$ & 0.346 \\
\hline \multicolumn{4}{|l|}{ Creatinine clearance $(\mathrm{mL} / \mathrm{min})$} \\
\hline Median $(Q 1-Q 3)^{\mathrm{C}}$ & $74.9(58.5-91.5)$ & $49.9(39.3-62.9)$ & $<0.001$ \\
\hline \multicolumn{4}{|l|}{ Serum creatinine $(\mu \mathrm{mol} / \mathrm{L})$} \\
\hline \multicolumn{4}{|l|}{ Contrast nephropathy risk score ${ }^{\mathrm{b} \#}$} \\
\hline$\leq 5$ (low) & $84(35.1 \%)$ & $2(3.3 \%)$ & $<0.001$ \\
\hline 6-10 (moderate) & $94(39.3 \%)$ & $38(63.3 \%)$ & 0.001 \\
\hline 11-16 (high) & $39(16.3 \%)$ & $17(28.3 \%)$ & 0.051 \\
\hline$\geq 17$ (very high) & $22(9.3 \%)$ & $3(5.1 \%)$ & 0.431 \\
\hline \multicolumn{4}{|l|}{ Medical conditions } \\
\hline Hypertension, $n(\%)^{b}$ & $179(74.9 \%)$ & $56(93.3 \%)$ & 0.001 \\
\hline Diabetes mellitus, $n(\%)^{b}$ & $114(47.7 \%)$ & $39(65 \%)$ & 0.012 \\
\hline Hyperlipidemia, $n(\%)^{b}$ & $139(58.2 \%)$ & $40(66.7 \%)$ & 0.229 \\
\hline Renal insufficiency, $n(\%)^{b}$ & $10(4.2 \%)$ & $21(35 \%)$ & 0.035 \\
\hline Ischemic heart disease, $n(\%)^{b}$ & 105 (43.9\%) & $25(41.7 \%)$ & 0.214 \\
\hline Congestive heart failure, $n(\%)^{\mathrm{b}}$ & $106(44.4 \%)$ & $28(51.7 \%)$ & 0.747 \\
\hline Anemia, $n(\%) ¥$ & $3(1.3 \%)$ & $4(6.7 \%)$ & 0.015 \\
\hline \multicolumn{4}{|l|}{ Medications } \\
\hline$A C E I / A R B, n(\%)^{b}$ & $151(63.2 \%)$ & $40(68.3 \%)$ & 0.552 \\
\hline Antiplatelets, $n(\%)^{b}$ & $226(94.6 \%)$ & $54(90 \%)$ & 0.318 \\
\hline Diuretics, $n(\%)^{b}$ & $78(32.6 \%)$ & $24(40 \%)$ & 0.355 \\
\hline$B B, n(\%)^{b}$ & $188(78.7 \%)$ & $47(78.3 \%)$ & 0.904 \\
\hline CCB, $n(\%)^{\mathrm{b}}$ & $38(15.9 \%)$ & $14(23.3 \%)$ & 0.242 \\
\hline Statins, $n(\%)^{b}$ & $186(77.8 \%)$ & $50(83.3 \%)$ & 0.557 \\
\hline Oral anti-diabetics, $n(\%)^{\mathbf{b}}$ & $145(60.7 \%)$ & $45(75 \%)$ & 0.056 \\
\hline
\end{tabular}

$N A C=N$-acetylcysteine,$B M I=$ body mass index, $A C E I=$ angiotensin-converting enzyme inhibitor, $A R B=$ angiotensin receptor blocker, $B B=\beta$-blocker, $C C B=$ calcium channel blocker, $Q 1-Q 3=$ lower quartile to upper quartile, \# Using Mehran risk score, ${ }^{a}$ Significance of differences estimated with Student's $t$-test;

${ }^{b}$ Significance of differences estimated with Chi square test; ${ }^{c}$ Significance of differences estimated with Mann-Whitney U-test.

\section{DISCUSSION}

The present study was conducted to investigate and compare the occurrence of RCIN among patients undergoing coronary angiography after pretreatment with standard saline hydration alone or standard saline hydration plus NAC as a preventive measure against RCIN.

In this study, RCIN was identified in 13 patients, making the incidence of RCIN among hospitalized patients undergoing coronary angiography in our study $4.3 \%$. This result was consistent with the 
Table 2: Comparison of surrogate markers related to radiocontrast-induced nephropathy among the two groups

\begin{tabular}{llll}
\hline & $\begin{array}{l}\text { Standard saline } \\
\text { hydration group } \\
\text { (N=239) } \\
\text { Median (Q1 -Q3) }\end{array}$ & $\begin{array}{l}\text { NAC + standard saline } \\
\text { hydration group (N=60) } \\
\text { Median }(\mathbf{Q 1}-\mathbf{Q 3})\end{array}$ & $P$-value \\
& $88(79.0-103.3)$ & $128(122-153)$ & \\
\hline Serum creatinine at $24 \mathrm{~h}(\mu \mathrm{mol} / \mathrm{L})$ & 1.2 & -2.1 & $<0.001$ \\
$\Delta$ Creatinine at $24 \mathrm{~h}(\mu \mathrm{mol} / \mathrm{L})$ & 1.3 & -0.6 & 0.039 \\
$\Delta$ Creatinine at $24 \mathrm{~h}(\%)$ & $89(76-101)$ & $129(116-144)$ & 0.042 \\
Serum creatinine at $48 \mathrm{~h}(\mu \mathrm{mol} / \mathrm{L})$ & 0.8 & -5.0 & 0.001 \\
$\Delta$ Creatinine at $48 \mathrm{~h}(\mu \mathrm{mol} / \mathrm{L})$ & 0.8 & -2.6 & 0.008 \\
$\Delta$ Creatinine at $48 \mathrm{~h}(\%)$ & 8.188 \\
\hline
\end{tabular}

Note: $\Delta=$ change, $N A C=N$-acetylcysteine, $Q 1-Q 3=$ lower quartile to upper quartile; Significance of all differences estimated with Mann-Whitney U-test.

reported incidence of $\mathrm{RCIN}$ in the general population, which ranges from 1 to $6 \%[14,15]$.

It was found that there were no differences between hydration with standard saline alone and hydration with standard saline plus NAC in protecting against the development of RCIN. Radiocontrast-induced nephropathy occurred in $3.3 \%$ of patients in the standard saline hydration group and $8.3 \%$ of patients in the NAC plus standard saline hydration group $(p=0.09)$. The higher incidence of diabetes, renal insufficiency, and other risk factors in the NAC plus standard saline hydration group may clarify the higher incidence of RCIN in this group. Moreover, those risk factors, i.e., hypertension, diabetes and renal insufficiency that showed significantly higher incidence among patients in NAC plus hydration group may explain the non-significance in the development of RCIN between the two groups. Furthermore, this result is consistent with previous a study that found that there was no benefit in adding NAC to standard hydration, in comparison to standard hydration by itself, for preventing RCIN among patients undergoing coronary angiography [16].

Patients in the NAC plus standard saline hydration group had higher median serum creatinine levels documented at $24 \mathrm{~h}$ than patients in the standard saline hydration group. This result may be be due to the fact that patients in the NAC plus standard saline hydration group had significantly higher renal insufficiency risk factor at baseline, compared to the standard saline hydration $(p=0.035)$. However, as estimated from the median change in serum creatinine, patients in the NAC plus standard saline hydration group, overall, had a greater reduction in percent serum creatinine, compared to the standard saline hydration alone group $(p=0.042)$.
The prophylactic oral administration of the antioxidant NAC to patients with renal impairment has been examined on the assumption that reactive oxygen species are involved in RCIN. However, a prospective, double-blind, placebo controlled, randomized clinical trial, concluded that there was no detectable derivable benefit from the prophylactic administration of oral NAC over an aggressive hydration protocol in patients with diabetes mellitus and chronic kidney disease [10]. Also, another clinical study reviewed by Fishbane et al showed mixed results [9]. Therefore, the use of NAC, although not recommended for all patients, may be appropriate for patients at very high risk of RCIN [17].

The present study showed that RCIN was associated with male gender, a history of renal failure, ischemic heart disease, and previous diuretics treatment. Limited data exist to determine the relative impact of gender on the development of RCIN. An American study showed that females are at a higher risk of developing RCIN after radiocontrast exposure [18], but such findings were thought to be the result of confounding factors such as age, and the presence of other risk factors, such as anemia among female patients. This could have made females appear to be at greater risk for developing RCIN. More women than men in all quartiles were found to have stage 2 chronic kidney disease before angiography [18]. Our findings showed that RCIN occurred in male patients only, probably because in both groups, there were more male patients than female patients and the male patients were at higher risk to develop RCIN than female patients. Although diabetes mellitus and renal disease have been clearly identified as risk factors for the 
Table 3: Demographic, risk factors and clinical characteristics by categories for patients who develop or didn't develop RCIN

\begin{tabular}{|c|c|c|c|c|}
\hline Risk factor & $\begin{array}{c}\text { Total } \\
(\mathrm{N}=299) \\
(\%)\end{array}$ & $\begin{array}{l}\text { RCIN patients } \\
(\mathrm{N}=13) ;(\%)\end{array}$ & $\begin{array}{c}\text { Non-RCIN } \\
\text { patients } \\
(\mathrm{N}=286) ;(\%)\end{array}$ & $p$-value \\
\hline \multicolumn{5}{|l|}{ Age $^{a}$} \\
\hline$\geq 70$ years & $22(7.3)$ & $1(7.7)$ & $21(7.3)$ & 0.962 \\
\hline$<70$ years & $277(92.7)$ & $12(92.3)$ & $265(92.7)$ & \\
\hline \multicolumn{5}{|l|}{ Gender ${ }^{a}$} \\
\hline Male & $211(70.6)$ & $13(100)$ & $198(69.2)$ & 0.017 \\
\hline Female & $88(29.4)$ & $0(0)$ & $88(30.8)$ & \\
\hline \multicolumn{5}{|l|}{ Ethnic group ${ }^{b}$} \\
\hline Malay & $129(43.1)$ & $4(30.8)$ & $125(43.7)$ & 0.048 \\
\hline Chinese & $102(34.1)$ & $2(15.4)$ & $100(34.7)$ & \\
\hline Indian & $67(22.4)$ & 7 (53.9) & $60(20.9)$ & \\
\hline Others & $1(0.3)$ & $0(0)$ & $1(0.4)$ & \\
\hline \multicolumn{5}{|l|}{ Obesity ${ }^{a}$} \\
\hline Obese & $41(13.7)$ & $1(7.7)$ & $40(13.9)$ & 1.0 \\
\hline Non-obese & $258(86.3)$ & $12(92.3)$ & $246(86)$ & \\
\hline \multicolumn{5}{|l|}{ Smoking status ${ }^{b}$} \\
\hline Active & $67(22.4)$ & $4(30.8)$ & $63(22)$ & 0.757 \\
\hline Former smoker & $99(33.1)$ & $4(30.8)$ & 95 (12.2) & \\
\hline Never smoked & $133(44.5)$ & $5(38.5)$ & $128(44.8)$ & \\
\hline \multicolumn{5}{|l|}{ Contrast nephropathy risk ${ }^{\# a}$} \\
\hline High risk patient & $212(70.9)$ & $9(69.2)$ & $203(71)$ & 0.892 \\
\hline Not high risk patient & $87(29.1)$ & $4(30.8)$ & $83(29)$ & \\
\hline \multicolumn{5}{|l|}{ Volume of radiocontrast media ${ }^{a}$} \\
\hline$\geq 100 \mathrm{~mL}$ & $8(2.7)$ & $0(0)$ & $8(2.8)$ & \\
\hline$<100 \mathrm{~mL}$ & $291(97.3)$ & $13(100)$ & $278(97.2)$ & 1.0 \\
\hline Diabetes mellitus present ${ }^{a}$ & $153(51.2)$ & $9(69.2)$ & $144(50.4)$ & 0.258 \\
\hline Renal insufficiency present ${ }^{a}$ & $31(10.4)$ & $5(38.5)$ & $26(9.1)$ & 0.006 \\
\hline Heart failure present ${ }^{a}$ & $134(44.8)$ & $5(38.5)$ & $129(45.1)$ & 0.638 \\
\hline Ischemic heart disease present ${ }^{b}$ & $130(43.5)$ & $11(84.6)$ & $119(41.6)$ & 0.003 \\
\hline Hyperlipidemia present ${ }^{b}$ & $179(59.9)$ & $2(15.4)$ & $177(61.9)$ & 0.001 \\
\hline Hypertension present $^{b}$ & $235(78.6)$ & $7(53.8)$ & $228(79.7)$ & 0.026 \\
\hline Anemia present ${ }^{a}$ & $7(2.3)$ & $1(7.7)$ & $6(2.1)$ & 0.27 \\
\hline ACEI + ARB present ${ }^{a}$ & $179(59.9)$ & $8(61.5)$ & $171(59.8)$ & 0.899 \\
\hline CCB present ${ }^{\mathrm{a}}$ & $52(17.4)$ & $4(30.8)$ & $48(16.8)$ & 0.193 \\
\hline Statins present ${ }^{a}$ & $236(78.9)$ & $10(76.9)$ & $226(79)$ & 0.74 \\
\hline Diuretics present ${ }^{a}$ & $102(34.1)$ & $9(69.2)$ & $93(32.5)$ & 0.013 \\
\hline
\end{tabular}

development of RCIN [19], less emphasis has been placed on other diseases that may be important risk factors.

All prescription medications used in all the patients undergoing coronary angiography had been withheld for at least $12-24 \mathrm{~h}$ prior to the procedure. The present study showed that previous diuretic use was associated with the development of RCIN. A previous study has reported that nephrotoxic medication, such as aminoglycosides and furosemide, as well as drugs that impair renovascular autoregulation, such as non-steroidal anti-inflammatory drugs and angiotensin-converting enzyme inhibitors, were risk factors for the development of RCIN [20].

\section{Limitations of the study}

One of the limitations of this study is the retrospective nature of the study itself. Therefore, this study lacks the ability to investigate variables that were missing from the data in the medical records. Another limitation is the differences in the baseline characteristics between the patients treated with standard saline hydration plus NAC 
and patients receiving standard saline hydration alone. These factors may confound the relationship between the treatment with NAC and the occurrence of RCIN. Finally, our data are limited to four days after the procedure. The onset of RCIN may occur later. Thus, measuring renal function within four days of the procedure may have underestimated the nephropathy risk.

\section{CONCLUSION}

Hydration with standard saline plus oral NAC before radiocontrast medium exposure may not be more effective than hydration with standard saline alone for prophylaxis of RCIN in patients undergoing coronary angiography. According to the online database from the National Medical Research Register of Malaysia, there is currently no registered research pertaining to this issue. Further Malaysian perspectives and multicenter clinical studies, as well as future prospective and controlled studies are needed to both estimate the true incidence and prevalence of RCIN and to estimate its financial burden on Malaysian hospitals. Moreover, more future prospective and controlled studies are needed to find the ideal preventive treatment for nephropathy induced by radiocontrast media after different procedures including coronary angiography.

\section{ACKNOWLEDGMENT}

The authors would like to thank the cardiology team at the Penang General Hospital including the nursing staff at the Laboratory of Interventional Cardiology. The assistance of the medical and record office staff is gratefully acknowledged.

\section{REFERENCES}

1. Efrati S, Dishy V, Averbukh $M$, Blatt A, Krakover $R$, Weisgarten J, Morrow JD, Stein MC, Golik A. The effect of $\mathrm{N}$-acetylcysteine on renal function, nitric oxide, and oxidative stress after angiography: Kidney Int 2003; 64: 2182-2187.

2. Al-Ghonaim M, Pannu N. Prevention and treatment of contrast-induced nephropathy. Tech Vasc Interv Radiol 2006; 9: 42-49.

3. Zagler A, Azadpour M, Mercado C, Hennekens $\mathrm{CH}$. $\mathrm{N}$-acetylcysteine and contrast-induced nephropathy: a meta-analysis of 13 randomized trials. Am Heart J 2006; 151: 140145.

4. Asif A, Epstein DL, Epstein M. Dopamine-1 Receptor Agonist: Renal Effects and Its Potential Role in the Management of
Radiocontrast-Induced Nephropathy. J Clin Pharmacol 2004; 44: 1342-1351.

5. Rudnick MR, Berns JS, Cohen RM, Goldfarb S. Nephrotoxic risks of renal angiography: contrast-media associated nephrotoxicity and atheroembolism - a critical review. Am J Kidney Dis 1994; 24: 713-727.

6. Mueller C. Prevention of contrast-induced nephropathy with volume supplementation. Kidney Int Suppl 2006 ; 100: S16-19.

7. Hoffmann U, Banas B, Fischereder M, Krämer BK. $\mathrm{N}$-acetylcysteine in the prevention of radiocontrast-induced nephropathy: clinical trials and end points. Kidney Blood Press Res 2004; 27: 161-166.

8. Kay J, Chow WH, Chan TM, Lo SK, Kwok OH, Yip $A$, Fan $\mathrm{K}$, Lee $\mathrm{CH}$, Lam WF. N-acetylcysteine for prevention of acute deterioration of renal function following elective coronary angiography and intervention: a randomised controlled trial. JAMA 2003; 289: 553-558.

9. Fishbane S, Durham JH, Marzo K, Rudnick M. Nacetylcysteine in the prevention of radiocontrast-induced nephropathy. J Am Soc Nephrol 2004; 15: 251-260.

10. Amini M, Salarifar M, Amirbaigloo A, Masoudkabir $F$, Esfahani F. N-acetylcysteine does not prevent contrast-induced nephropathy after cardiac catheterization in patients with diabetes mellitus and chronic kidney disease: a randomized clinical trial. Trials. 2009; 10: 45.

11. Namasivayam S, Kalra MK, Torres WE, Small WC. Adverse reactions to intravenous iodinated contrast media: a primer for radiologists. Emerg Radiol 2006; 12: 210-215.

12. Cockcroft DW, Gault MH. Prediction of creatinine clearance from serum creatinine. Nephron 1976; 16: 31-41.

13. Mehran R, Aymong ED, Nikolsky E, Lasic Z, lakovou I, Fahy M, Mintz GS, Lansky AJ, Moses JW, Stone GW et al. A simple risk score for prediction of contrast induced nephropathy after coronary intervention. J Am Coll Cardiol 2004; 44: 1393-1399.

14. Rudnick MR, Goldfarb S, Wexler L, Ludbrook PA, Murphy MJ, Halpern EF, Hill JA, Winniford M, Cohen $M B$, VanFossen $D B$. Nephrotoxicity of ionic and nonionic contrast media in 1196 patients: a randomized trial. The lohexol Cooperative Study. Kidney Int 1995; 47: 254261.

15. Waybill MM., and Waybill PN. Contrast mediainduced nephrotoxicity: identification of patients at risk and algorithms for prevention. $J$ Vasc Interv Radiol 2001; 12: 3-9.

16. Gulel O, Keles T, Eraslan H, Aydogdu S, Diker E, Ulusoy V. Prophylactic acetylcysteine usage for prevention of contrast nephropathy after coronary angiography. $J$ Cardiovasc Pharmacol 2005; 46: 464-467.

17. Schweiger MJ, Chambers CE, Davidson CJ, Blankenship J, Bhalla NP, Block PC, Dervan JP, Gasperetti C, Gerber L, Kleiman NS et al. 
Hassan et al

Prevention of contrast induced nephropathy: recommendations for the high risk patient undergoing cardiovascular procedures. Catheter Cardiovasc Interv 2007; 69: 135-140.

18. Sidhu RB, Brown JR, Robb JF, Jayne JE, Friedman $B J$, Hettleman BD, Kaplan AV, Niles NW, Thompson $C A$. Interaction of gender and age on post cardiac catheterization contrastinduced acute kidney injury. Am J Cardiol 2008; 102: 1482-1486.
19. McCullough PA, Wolyn R, Rocher LL, Levin RN, O'Neill WW. Acute renal failure after coronary intervention: incidence, risk factors, and relationship to mortality. Am J Med 1997; 103: $368-375$.

20. Baker LRI. Drugs and the kidney. In: Kumar $P$, Clark $M$, eds. Clinical medicine, 4th ed. London, England: Saunders, 1998; pp 565567. 